\title{
Die rol van die ouers van Simson in die Simsonsage (Rigters 13-16)
}

J H Coetzee

\section{ABSTRACT}

The role of the parents of Samson in the Samson saga (Judges 13-16)

The parents of Samson, Manoah and his wife, play an important literary and theological role not only in Judges 13 where they act as main characters, but also in the rest of the saga where they occur in a diminishing role. By means of the interaction between the characters and the underlying motifs originating from them (especially the parents), Samson's conduct in relationship with his parents becomes an illustration of the tension found in the life of the people of Israel, viz. that between the orderly social institutions on the one hand and the natural non-traditional forces in a developing society on the other hand.

\section{INLEIDING}

Deeglike navorsing is reeds oor 'n wye spektrum van onderwerpe rakende die Simsonsage (Rigt 13-16) gedoen. In hierdie artikel word daar egter gekonsentreer op die literêre en teologiese rol en funksie wat Simson se ouers as karakters in hierdie sage as geheel speel, aangesien hierdie aspek nog onvoldoende aandag gekry het in die navorsing. Aangesien Simson se ouers veral in Rigters 13 baie prominent ter sprake is en hierdie hoofstuk ook die inleiding tot die sage in geheel is, ontvang hoofstuk 13 besondere aandag binne die konteks van die hele sage. Met in agneming van die intrigelyn word die karakters Manoag asook sy vrou van nader geanaliseer om aan te toon hoe hulle met die hoofkarakter Simson in verband staan. Die verbintenis tussen die ouers en Simson is veral belangrik indien aangeneem word dat elkeen van die rigters in die boek as geheel iets van die lewe van die volk Israel uitbeeld en dat Simson se verhaal dus ook op 'n unieke wyse die volk se wel en weë verteenwoordig1. Hierdie uitgangspunt hang saam met die aanname van 'n redaksionele raamwerk waarbinne die verhale van die rigters geplaas is, naamlik dat die volk telkens afvallig raak, dat die Here hulle straf met 'n heidenvolk wat hulle teister, en dat God, nadat die volk om hulp geroep het, aan hulle 'n rigter skenk om hulle te red ${ }^{2}$. 


\section{DIE INTRIGE}

Om met 'n ondersoek van die karakters van 'n vertelling besig te wees beteken dat die intrige van die sage ernstig geneem moet word ${ }^{3}$. Alhoewel die karakters in die verskillende sages in die boek Rigters nie so ontwikkel dat hulle die intrige van die boek op makrovlak beïnvloed nie ${ }^{4}$, vind daar tog karakterontwikkeling binne individuele sages self plaas wat van belang is vir die verstaan van die intrigelyne van die individuele sages.

Die intrigelyn in Rigters 13-16 lê tussen twee pole. Dit begin aan die een kant met die stelling in 13:1 dat God kwaad is vir Israel weens hul sonde en dat Hy hulle vir veertig jaar lank oorgee in die mag van die Filistyne. Aan die ander kant beloof Hy egter 'n leier (13:5) wat die volk moet red uit die mag van die Filistyne. Hierdie leier regeer vir twintig jaar lank (vgl 16:31) oor Israel. Ná die geboorteverhaal in hoofstuk 13 wat sterk teologies ingekleur is, draai die res van die intrige om die verwagtings aangaande Simson se rol as nasireër in die redding van Israel uit die mag van die Filistynes. Weens Simson se profane optrede word hierdie verwagtings egter nie in die res van die vertelling werklik verwesenlik nie 6 . Dit is dus legitiem om te vra na die verteller se bedoeling met hierdie onvervulde verwagtings. Simson se ouers, wat veral in hoofstuk 13 'n prominente rol speel, hou direk met hierdie verwagtings verband.

Aangesien Simson se ouers in Rigters 13 as hoofkarakters (saam met die Engel) aan die leser voorgehou word, maar in die res van die vertelling as sekondêre karakters ${ }^{7}$, word hoofstuk 13 vervolgens van nader belig.

\section{DIE SAMESTELLING VAN RIGTERS 13}

Die samestelling van hoofstuk $13^{8}$ wys op 'n aantal interessante aspekte rakende die verskillende karakters wat aanvanklik aan die leser voorgestel word, naamlik Manoag, sy vrou, die Engel van die Here en Simson. Die perikoop bestaan uit drie hoofindelings $(3-7 ; 8-20 ; 21-23)$ wat omraam word deur verse 2 en 24-25. Vers 1 is 'n redaksionele inleiding tot beide hierdie perikoop en die Simsonsage in sy geheel ${ }^{9}$. Die seksies wat handel oor die twee verskynings van die Engel van die Here, eers slegs aan die vrou van Manoag (3-7), daarna weer aanvanklik slegs aan haar, en dan aan haar en Manoag saam (8-20), hou ten nouste met mekaar verband. Verse 24-25 beskryf Manoag en sy vrou se reaksie op die verdwyning van die Engel. Die omraming van die eerste perikoop word gevorm deur die 
kontrasterende motiewe van die kinderlose vrou (vers 2) en die vrou wat 'n kind in die lewe bring (vers 24 ), asook deur die voorkoms van die name Sora en Daniete/Dan (verse 2 en 25). Die verbinding van die name Sora en Dan met Manoag in vers 2 word in vers 24-25 vervang met die naam van Simson wat verbind word met die kamp van Dan tussen Sora en Estaol. Bogenoemde motiewe en name kom in 'n chiastiese patroon in die genoemde verse voor.

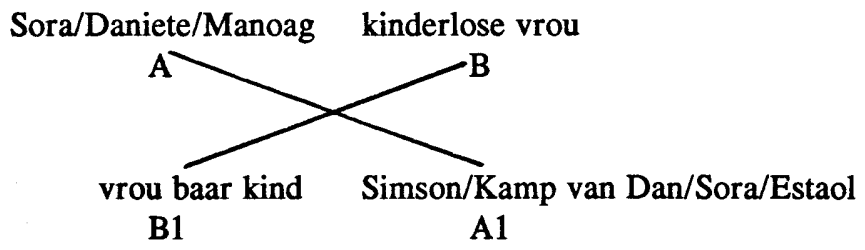

Hierdie chiastiese omraming dui op 'n fokusverskuiwing vanaf die ouers (Manoag en sy vrou) na die eintlike (menslike) hoofkarakter van die sage, naamlik hul seun Simson. Vers 25 vorm 'n oorgang na hoofstuk 14 waar sowel Simson as sy ouers as karakters funksioneer, maar laasgenoemde in 'n al hoe geringer mate. In hoofstuk 14 vervul Simson die hoofrol, terwyl sy ouers gesamentlik, en nie ook afsonderlik soos in hoofstuk 13 nie, optree.

Hoofstuk 13 waarin die ouers van Simson 'n primêre rol speel, kan op grond van bogenoemde bespreking struktureel soos volg voorgestel word:

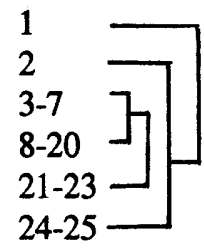

Die wyer konteks (hoofstuk 13-16) waarbinne hoofstuk 13 val, toon duidelik dat hierdie hoofstuk die inleiding tot die res van die vertellings in die Simsonsage vorm ${ }^{10}$. Die primêre fokus van hoofstuk 13 is om die hoofkarakters van die res van die sage, naamlik Simson en die Here, asook sekere temas wat later in die sage 'n rol speel, aan die leser voor te stel'1. Om hierdie doel te bereik word die leser reeds vroeg in die vertelling aan die ouers van die kind wat gebore moet word voorgestel. Exum ${ }^{12}$ sien die 
ouers as die eintlike hoofkarakters van hoofstuk 13. Die meeste geleerdes beskou die vrou van Manoag as die protagonis ${ }^{13}$, terwyl die Engel weer deur ander as die hooffiguur in hierdie hoofstuk gereken word ${ }^{14}$. $\mathrm{Na}$ my mening speel al drie (Manoag, die vrou en die Engel) onderskeidelik prominente rolle in die onderskeie seksies waaruit die perikoop bestaan. In verse 2-3 word die drie aktiewe karakters aan die leser voorgestel. Daarna neem die Engel die leiding (3-5). Die vrou neem die leiding oor deur met haar man Manoag gesprek te voer oor die Engel se verskyning aan haar (67). Dan neem Manoag inisiatief met 'n gebed waarin hy versoek dat die Engel weer aan hulle moet verskyn (8). Die Engel verskyn weer aan die vrou (9), die vrou vertel dit aan Manoag (10), en Manoag gaan praat met die Engel (11-18). Daarna gaan Manoag tot handeling oor deur die offerritueel uit te voer (19). Let op die lengte van Manoag se gesprek met en optrede teenoor die Engel (11-20). Waar dit in die eerste deel van die perikoop voorkom asof Manoag 'n ondergeskikte rol speel, word sy aandeel as karakter in die tweede en veral in die derde deel van die vertelling stilisties baie sterk beklemtoon. Daardeur wil die verteller 'n bepaalde klem op Manoag as karakter plaas wat egter terselfdertyd ook gedemp word deur die optrede van die ander twee karakters, naamlik sy vrou en die Engel. Die vinnige afwisseling van karakterkombinasies in hoofstuk 13 verlewendig die verhaal en bring die funksie van elke karakter sterk na vore, terwyl die verteller hom haas om by die hoofkarakter, Simson, uit te kom.

\section{DIE LITERERE EN TEOLOGIESE FUNKSIES VAN SIMSON SE OUERS}

'n Opvallende en veel gedebateerde aspek in die bekendstelling van Simson se ouers is die feit dat sy vader se geografiese (die dorp Sora) en genealogiese (uit die stam van Dan) herkoms asook sy naam (Manoag) pertinent genoem word, terwyl sy moeder slegs aan die lesers voorgestel word as: "Sy vrou was kinderloos" (13:2). Die feit dat Manoag se vrou nêrens in die sage by haar naam genoem word nie, het heelwat navorsers in die rigting laat beweeg om die rolle en funksies van die vader en moeder van Simson teenoor mekaar af te speel ${ }^{15}$. Manoag, die vader van Simson, speel volgens sommige navorsers 'n a-tipiese rol as manlike karakter. Byna deur die bank word gewys op die ondergeskikte, passiewe rol wat hy veral in hoofstuk 13 in vergelyking met sy vrou inneem ${ }^{16}$. Die neiging om dié twee karakters egter net negatief teen mekaar af te speel ${ }^{17}$, lei daartoe dat hulle onderskeie en gesamentlike rolle en funksies binne die vertelling 
verskraal word. Daarom sal die literêre en teologiese funksies van Simson se ouers vervolgens belig word.

\subsection{Manoag}

Die persoonsnaam "Manoag" asook die pleknaam "Sora” omraam die hele Simsonsage (vgl Rigt 13:2 en 16:31), waardeur die familiegebondenheid (sosiale aspek) en plekgebondenheid (ruimtelike aspek) waarbinne die Simsonsage as geheel afspeel, aangedui word. Hierdie is 'n belangrike funksie wat die karakter Manoag in die sage het, aangesien hy eksemplaries die "gevestigde kultuur" 18 van Israel gedurende die rigtertyd in die sage uitbeeld.

Kyk 'n mens na die optrede van Manoag in Rigters 13, dan kom die volgende na vore:

* Alhoewel sy naam met "rus" verband hou, tree hy allermins rustig op. Direk nadat sy vrou hom van haar ontmoeting met die Engel vertel het, het hy tot die Here gebid (13:8);

* Direk nadat sy vrou hom van die tweede verskyning van die Engel aan haar vertel het, staan hy op en volg haar dadelik om met die Engel te gaan praat (13:11);

* Manoag is haastig om te weet hoe die kind wat gebore gaan word hom moet gedra, en dus wat hulle as ouers se aandeel aan sy opvoeding spesifiek moet behels (13:12);

* Hy wil ook dadelik vir die Engel 'n bokkie gaar maak (13:15). Alhoewel die Engel die maaltyd saam met Manoag van die hand wys, gaan Manoag voort en offer dit aan die Here (13:19). 'n Vreemde abruptheid word in die verhaal geskep wanneer Manoag se vraag in vers 12-13 nie werklik direk beantwoord word nie, terwyl hy direk daarna die gespreksonderwerp verander.

* Toe Manoag en sy vrou die Engel in die altaarvlam sien opstyg, het hulle onmiddellik op die grond neergeval.

Dit is dus baie duidelik uit Manoag se optrede dat hy as 'n dinamiese, en tot 'n mate 'n impulsiewe mens voorgestel word wat sterk leiding kan neem. Dit berei die leser voor op die optrede van die eintlike hoofkarakter, Simson. 
Manoag word egter nie deurgaans in so 'n positiewe lig geteken nie. So, byvoorbeeld, word hy deur die verteller geskets as 'n eggenoot wat tot 'n mate in die skaduwee van sy vrou beweeg. In 13:2 ontvang hy nog prominensie omdat hy eerste genoem word en sy vrou "aan hom gekoppel" word. In die twee verskynings van die Engel ontvang die vrou egter prominensie deurdat Manoag aanvanklik doelbewus uitgesluit word, selfs nadat hy gebid het dat "die man van God" die tweede keer aan "ons" moet verskyn (13:8). Manoag se gebed word dus anders verhoor as wat sy eie bedoeling was. Tydens sy ontmoeting met die Engel herken hy Hom nie as die Engel van God nie, terwyl sy vrou intuitief aanvoel dat Hy "gelyk het soos 'n engel van God" (13:6). Manoag se vraag oor die opvoeding van die seun word ook nie direk deur die Engel beantwoord nie, maar die Engel se antwoord rig die fokus op die vrou (13:12-14). Manoag se gasvryheid word deur die Engel van die hand gewys omdat hy nie voldoende insig het in met wie hy te doen het nie (13:15-18).

Ook in 13:22-23 stel Manoag se vrees vir die dood omdat hulle die Here gesien het (13:22) en sy vrou se "meerdere teologiese insig" dat God hulle nie sal laat sterf nie weens sy belofte van die kind (13:23), hom oënskynlik in sy vrou se skaduwee ${ }^{19}$. Waaroor dit egter meer waarskynlik hier handel, is 'n uitbeelding van Manoag se godsdiensbelewenis as sterk verbonde aan die reëls van die godsdiens (vgl Eks 33:20)20. Sy gereguleerde godsdiensbelewenis oorskadu dus sy visie op God se belofte van 'n kind.

Bogenoemde positiewe en negatiewe karaktereienskappe toon aan dat Manoag die voorbeeld van die "gevestigde orde" is, maar dat sy optrede nie altyd sinvol is nie al is sy bedoelings goed en sy insig in wat gebeur beperk.

Die motiewe van "weet" en "nie-weet nie" word in hoofstuk 13 vanuit Manoag as karakter geïnisieer ${ }^{21}$. Manoag se beperkte insig in die werk van die Here volgens hoofstuk 13 bring die wonderaspek van sy vrou se bevrugting 22 op die voorgrond en daardeur die feit dat die Here op 'n misterieuse wyse in die agtergrond werksaam is ${ }^{23}$. Ook in die res van die verhaal waar Simson en sy ouers ter sprake is, speel hierdie motief ' $n$ rol $(14: 4 ; 16: 20)$ en beklemtoon dit die feit dat die Here in die lewens van mense werksaam is. Let op dat selfs Manoag se vrou wat in hoofstuk 13 meer insig as Manoag het, in 14:4 'n gebrek aan insig in die Here se werk toon.

Manoag se impulsiewe, dinamiese en soms oënskynlik minder sinvolle optrede kenmerk ook die lewe van Simson. Vergelyk byvoorbeeld die aandrang by sy ouers om vir hom 'n Filistynse vrou te kry (14:1-3); sy 
doodmaak van die leeu (14:6) terwyl hy op pad is na die vrou met wie hy wou trou asook sy skielike afdraai om na die geraamte van die leeu te gaan kyk (14:8); sy doodslaan van die dertig man (14:19); sy vang van die driehonderd jakkalse en die aan die brand steek van die Filistyne se graanlande, wingerde en olyfboorde (15:4-5); sy doodmaak van 'n klomp Filistyne (15:8); sy doodmak van 'n duisend Filistyne met die donkiekakebeen (15:15); sy onverwagse afdraai na die prostituut toe (16:1); sy (skielike) verliefraak op Delila (16:4). Dit is interessant dat die Here agter baie van hierdie impulsiewe dade van Simson sit (13:25; $14: 6,19 ; 15: 14,19 ; 16: 28)$. Sodoende word die motief van die redding uit die mag van die Filistyne voortgesit, asook die Here se inisiatief daarin.

Manoag tree as 'n goeie gasheer teenoor "die man van God" op (13:1518). Getrou aan die normale gebruike van gasvryheid (vgl Gen 18:1-8; $19: 1-8 ; 24: 28-32$; Rigt $6: 19 ; 19: 16-21$ ) bied hy Hom 'n ete aan. Die indruk word deur die verteller geskep dat die uiterlike korrekte optrede vir Manoag baie belangrik is. $\mathrm{Hy}$ is die tradisievaste en die konvensionele karakter in die verhaal. Hy het ook geglo dat die Here vir hulle "reëls" sal gee oor hoe om die kind groot te maak $(13: 8,12)$. In hoofstuk 14 funksioneer Manoag meer prominent as sy vrou om sodoende op hierdie tradisievastheid klem te lê (vgl 14:3). Later in die vertellings blyk dat dit by Simson net die teenoorgestelde is. $\mathrm{Hy}$ is die onkonvensionele karakter deur wie die kontras tussen kultuur en natuur, tussen ordelike sosiale instellings en wilde, ongekontroleerde kragte uitgebeeld word ${ }^{24}$. Klein vat Simson as karakter goed saam wanneer sy sê: "He is full of high spirits and low ethics" 25. Manoag se "onkundige" gasvryheid kom in 13:17 tot 'n hoogtepunt met die vraag aan die Engel: "Wat is u naam?". Die antwoord van die Engel (13:18) verskuif die klem van Manoag se gasvryheid na die wonderaspek (verse 18 en 19) in die vertelling, en daarmee implisiet na die wonder van die kind wat vir die kinderlose egpaar gebore sou word. 'n Skynbaar sinlose poging van Manoag om van nader kennis met die Engel te maak loop dus uit op 'n "verskuilde openbaring" van God se wondermag.

Die raaiselmotief in die lewe van Manoag, naamlik dat hy nie direk 'n antwoord op sy vraag oor die opvoeding van die kind kry nie, speel 'n belangrike rol in die res van die verhaal en ook in die lewe van Simson. Aanvanklik (13:12-14) help hierdie motief om die fokus op die vrou te plaas, terwyl Manoag in die duister gelaat word. Hierdie "raaisel" se oplossing word nie direk weergegee nie, maar die oplossing lê verskuil in die kontras tussen Manoag en sy vrou se piëteit met betrekking tot die nasireërskap van hul seun teenoor Simson se negering van die nasireër- 
riglyne waarvolgens hy behoort te lewe. Hoofstuk 14:12-20, wat handel oor die raaisel van die heuning in die leeukarkas, lei tot die einde van Simson se huwelik en tot verskeie geleenthede om die Filistyne uit te roei. Die raaisel van Simson se krag wat deur Delila op 'n slinkse wyse ontrafel word (hoofstuk 16), vorm die hoogtepunt van die verhaal omdat dit sy nasireërskap neutraliseer en lei tot sy eie dood asook dié van baie Filistyne. Die ontwikkeling van die raaiselmotief wat aanvanklik in Manoag as karakter geïnisieer word, het uiteindelik ten doel om die spanning in die vertelling te laat styg. Die Engel se raaiselagtige swye teenoor Manoag oor Simson se nasireërskap, Simson se moeder se toevoeging dat hy "tot met sy dood" aan God gewy sal wees (13:7), en Simson se bekendmaking van die raaisels rondom sy nasireërskap vorm elemente van die spanningslyn wat op sy dood uitloop.

\subsection{Die vrou van Manoag}

Die opvallendste kenmerke van die vrou van Manoag is die feit dat die verteller nie haar eienaam gebruik om haar te identifiseer nie en dat sy kinderloos is. In hoofstuk 13 word die vrou net "die vrou" $(3,6,9,10,11$, 13,24 - sewe keer) en "sy vrou" $(2,11,19,20,21,22,23$ - sewe keer) genoem, en verder word sy met behulp van voornaamwoorde aangedui. Sou dit kon wees dat haar naam verswyg word omdat sy kinderloos was en dit gesien is as "a sign of reproach and divine displeasure"?26. In die aartsvaderverhale word Sara, Rebekka en Ragel en in die boek Samuel word Hanna wel by die naam genoem as kinderlose vroue. Kinderloosheid is gekoppel aan ' $n$ naam en is dus nie 'n vreemde verskynsel nie. Daar moet na ander moontlike redes gesoek word vir die verswyging van Manoag se vrou se naam in Rigters 13-16.

Deur Manoag se vrou se anonimiteit word daar eerstens baie sterker klem op die naam en afkoms van Manoag self gelê (uit Sora uit die stam van Dan [13:2]) om sodoende die aspek van gevestigdheid en ordelikheid te beklemtoon. Verder beklemtoon dit ook die probleem rondom die naam van die Engel van die Here (13:17-18) wat eintlik heenwys na die wonderaspek in die verhaal. 'n Derde rede kan ook wees dat die klem in die sage as geheel eerder op Simson se Filistynse meisie, Delila (Rigt 16), as op sy moeder lê. Dit is opvallend dat Simson se vrou, soos sy moeder, ook nie met haar eie naam aangedui word nie $(14: 1,2,3,7,8,10,15,16$, $17,20 ; 15: 1,2,6)$. Ook die prostituut by wie hy 'n gedeelte van 'n nag in Gasa deurgebring het bly naamloos (16:1-3). En dan, skielik, word die naam van sy tweede meisie, Simson se eintlike verleier en sy uiteindelike 
vernietiger, baie prominent in 16:4 genoem: Delila, 'n Filistynse vrou uit die Sorekvallei. Delila vorm so die teenpool van Manoag se anonieme vrou wat deur haar noue verbintenis met die Engel ${ }^{27}$ self aan die vereistes van die nasireërskap wat sy aan Simson moet oordra, voldoen. Aan die begin van sy lewe gee Simson se naamlose moeder hom 'n naam en maak hom as nasireër groot. Sy noem hom Simson (wat “lig/son” beteken). Teen die einde van Simson se lewe kom daar egter deur sy eie toedoen 'n vrou met 'n naam in sy lewe, naamlik Delila (wat "nag" beteken) ${ }^{28}$, wat hom van sy nasireërskap stroop en finaal letterlik en figuurlik nag in sy lewe bring. Simson word dus deur 'n vrou (sy moeder) aanvanklik in die "goeie wêreld" ingebring. Daarna beland hy deur sy eie toedoen in die "verkeerde wêreld" wanneer hy met die Filistynse vrou trou (14:1-15:6). Deur sy eie toedoen daal hy al dieper af in die "verkeerde wêreld" deur by 'n prostituut te gaan slaap (16:1-3) en daarna weer verlief te raak op 'n Filistynse vrou (Delila) vir wie hy nie met sy lewensgeheim kan vertrou nie $(17: 4-22)$.

Die motief van die kinderloosheid van die vrou van Manoag plaas die klem op die wonderkrag van God wat self die redding van sy volk bewerkstellig. Volgens De Vaux ${ }^{29}$ is kinderloosheid beskou as 'n beproewing (Gen 16:2; 30:2; 1 Sam 1:5), of as 'n kastyding van God (Gen 20:18), of as 'n skande waarvan vroue soos Sara, Ragel en Lea hulself wou bevry deur hul mans aan te moedig om kinders by hul slawemeisies te verwek en dan die kinders as hul eie aan te neem (Gen 16:2; 30:3,9). In die vertelling van Rigters 13 word niks hiervan gemeld nie en Manoag se vrou maak ook nie ander planne om haar van haar lot te bevry nie. Sy aanvaar dus haar lot gelowig. Sy is egter opgewonde oor die goeie nuus van die Engel dat sy reeds swanger is en 'n seun in die lewe sal bring, wat 'n groot eer vir 'n vrou was sodat die familienaam voortgesit kan word ${ }^{30}$. Deur 'n wonder van God word haar onvrugbaarheid dus verander sodat sy 'n seun baar (13:24) ${ }^{31}$.

Klein ${ }^{32}$ is van mening dat daar in die verhaal 'n verband tussen die konsepsie, die geboorte en die voorgeskiedenis van Israel bestaan. Die swangerskapstyd van die vrou waartydens sy aan die reëls van nasireërskap moet voldoen, beeld die wordingsproses van die volk uit. Die hoë verwagtings wat God rondom Israel koester in sowel die voorbereidingsfase as die res van haar geskiedenis en die uiteindelike tekortkominge van die volk word dramaties in die lewens van beide die moeder en die seun Simson uitgebeeld.

Manoag se vrou se geloof kan as intuïtiewe geloof ${ }^{33}$ tipeer word wat op grond van haar kommunikasie met die Engel die wonderaspek van wat 
gebeur, aanvoel. Toe Manoag skrik en vreesbevange is nadat hy besef het hulle het die Here gesien (13:21-23), kon sy hom met haar dieper geloofsinsig gerusstel. Hierdie intuitiewe geloof ontbreek by Manoag wat 'n tradisiegebonde geloof beoefen. Iets van die tradisionele godsdiens van die volk waardeur hulle verblind word om die wonderdade van die Here raak te sien, teenoor 'n natuurlike en intuïtiewe godsbelewenis wat 'n mens van die godsvolk sou verwag, word waarskynlik in die lewens van Manoag en sy vrou aan die leser voorgehou ${ }^{34}$.

Ten nouste hieraan verbind is die gehoorsaamheid van die vrou van Manoag. Die feit dat die opdrag van die Engel in verband met die vrou se gedrag tydens swangerskap (ter wille van die kind wat sy verwag) drie keer in die verhaal herhaal word $(13: 4-5,7,13-14)$, lê groot klem op die aspek van die vrou se gehoorsaamheid aan die opdrag. Hierdie aspek staan in skrille kontras met die ander vroue in Simson se lewe waar bedrog teenoor hom as man 'n pertinente rol speel. Ook staan sy moeder se gehoorsaamheid aan die nasireërvoorskrifte in skerp kontras met Simson se eie ongehoorsaamheid met betrekking tot sy nasireërskap.

Die noue verbintenis tussen Manoag en sy vrou as getroude paar blyk onder andere uit die feit dat Manoag se vrou twee keer (13:6-7, 10) nadat die Engel aan haar verskyn het direk na Manoag toe gaan om die verskyning aan hom mee te deel. Sy is gretig (v 10) om haar ervarings met haar man deel, want dit gaan reeds oor iets waarop hulle saam hoop, naamlik swangerskap. Behalwe tydens die verskynings van die Engel aan die vrou alleen, word daar volgens hoofstuk 13 en 14 deurgaans genoem dat sy saam met haar man rondbeweeg. Die huweliksband is aanvanklik ook vir Simson van belang terwyl hy nog in sy ouerhuis woon (14:2-3) en hulle 'n sterk houvas op hom het. Die verwagting dat hy met 'n vrou uit Israel sal trou en die gevestigde tradisie sal voortsit, word egter nie verwesenlik nie omdat hy 'n Filistynse vrou verkies. Weldra breek hy egter verder weg en gaan slaap by 'n prostituut (16:1-3) en raak verlief op nog 'n Filistynse meisie, Delila, wat hom uiteindelik sou verraai en sy dood sou veroorsaak. Die noue verbintenis tussen Manoag en sy vrou loop uit op lewe, naamlik die babaseuntjie Simson. Daarteenoor is die verbintenis tussen Simson en die Filistynse vroue egter 'n stelselmatige emansipasieproses ${ }^{35}$ wat uitloop op die dood van sy vrou en van baie mense en uiteindelik op Simson se eie dood. Hierdie kontras verbeeld die kontras tussen dit wat die Here van sy volk verwag en dit wat hulle doen deur met die heidene te vermeng ${ }^{36}$. 
Die karakters in die Simsonsage hou ten nouste met die uitbouing van die intrige verband. Die ouers van Simson speel aanvanklik veral in hoofstuk 13 'n baie prominente rol. In hierdie hoofstuk word daar egter deur Manoag en sy vrou as karakters op 'n baie subtiele wyse motiewe van karaktereienskappe en optrede in die verhaal geplant wat dwarsdeur die verhaal ' $n$ rol speel en wat uiteindelik bepalend is vir die verstaan van die verhaal in sy geheel binne die konteks van die finale redaksie daarvan.

Voor sy geboorte reeds word die boustene van die verhouding tussen Simson en sy ouers deur middel van die woorde van die Engel van God gelê (13:5, 7 en 12). Direk na sy geboorte gee sy moeder hom 'n naam en daar word net gemeld dat hy grootgeword het (13:24). Van die begin af het die Here vir Simson as redder van Israel geseën en gelei $(13: 24,25 ; 14: 6$, $19 ; 15: 14,19 ; 16: 28)$. In hoofstuk 14 blyk dat hy as volwasse jongman aanvanklik steeds noue kontak met sy ouers gehad het en dat hy, soos die gebruik was, van hulle afhanklik was vir die verkryging van 'n vrou (14:2$7,10)$. Daarna speel sy ouers nie verder 'n direkte rol in die verhaal nie, behalwe heel aan die einde (16:31) waar vermeld word dat Simson in die graf van sy vader begrawe word.

Simson se verhouding met die Here en met sy ouers word deur sy eie toedoen vertroebel deurdat hy Filistynse vrouens in die geheime van sy lewe inlaat. Deur nie aan die verwagtings te voldoen wat in hoofstuk 13 geskep word rondom die karakter Simson en sy nasireërskap nie, beweeg hy willens en wetens uit die geordende wêreld waarvan sy ouers die prototipe is na die chaotiese wêreld. Dit dui op 'n satiriese opgang in die verhaal. Sodoende lewer die verteller in werklikheid ironiese kommentaar op die waardes en voorstellings van die alledaagse bestaan in die lewe van die volk ${ }^{37}$.

Uiteindelik sluit die sage af met klimaktiese ironie: Simson se broers en sy hele familie kom haal sy lyk om hom in sy pa, Manoag, se graf te begrawe tussen Sora en Estaol (16:31). Die Here se doel met Simson het geslaag, naamlik dat hy begin het om Israel van die Filistyne te bevry. Maar Simson, wat met krag weggebreek het uit die gewone, tradisionele lewe, word na sy dood weer na die tradisionele plek van sy familie terug gebring. Hieruit blyk dat Simson se veelbesproke lewe die lewe van die volk in 'n ironiese lig stel. Hy word geroep om binne die gevestigde lewe "iets anders te wees" om sy volk te kan red en vir hulle 'n voorbeeld te wees. Hy verval egter in sonde wat uiteindelik tot sy dood lei. Deur die lewensintriges heen groei Simson/Israel self geestelik nie veel nie. 
Uiteindelik seëvier die tradisionele, die wêreld van Manoag as die prototipe van die tradisionele, op 'n ironiese wyse. Die wrang vrugte van die misbruik van Simson (en Israel) se roeping deur die vermenging met die heidenvolke bring doodse verstarring in die lewe van beide. Die "dodelike sirkel" is weer eens voltooi soos by die beskrywing van die vorige groot rigters. En tog, te midde van die kontras tussen die tradisionele en die vrye lewe van die volk soos uitgebeeld in die lewens van Simson en sy ouers verwesenlik God sy plan deurdat Simson die volk begin verlos van die Filistyne sodat hulle in die beloofde land kan vestig.

\section{NOTAS:}

1 L R Klein, The triumph of irony in the book of Judges, Sheffield 1989, 116.

2 J Gray, Joshua, Judges, Ruth, Grand Rapids 1986, 191 (Rigt 3:7-11, 12-15a en 30 ; 4:1a, 2a, 3a en 23-24; 5:31c; 6:1-2a, 7-10; 8:28, 33-35; 10:6-16; 11:33b).

$3 \quad$ P J Nel, "Character in the book of Judges", OTE 8 (1995), 194-195.

$4 \quad$ Nel, $a w, 191-204$.

$5 \quad$ Nel, $a w, 191-204$.

6 J C Exum, "The theological dimension of the Samson saga”, VT 33 (1983), 35.

7 Vergelyk S Bar-Efrat, Narrative art in the Bible, Sheffield 1989, 86-87 vir die stelling dat sekondêre karakters in een vertelling primêre karakters kan word in ' $n$ ander vertelling.

8 Vir 'n detailanalise, maar wat van my eie analise verskil, vergelyk J C Exum, "Promise and fulfillment: Narrative art in Judges 13", JBL 99 (1980), 43-59.

9 K F D Römheld, “Von den Quellen der Kraft (Jdc 13)”, ZAW 104 (1992), 3031; R G Boling, Judges. Introduction, Translation, and Commentary, Garden City 1975, 218.

10 J C Exum, "Aspects of symmetry and balance in the Samson saga", JSOT 19 (1981), 10; Reinhartz, a w, 25.

11 Reinhartz, $a w, 26$; Exum, $a w, 1983,30-45$.

12 Exum, $a w, 1981,4$.

13 S Niditch, "Samson as culture hero, trickster, and bandit: The empowerment of the weak", CBQ 52/4 (1990), 608-609; R Schaafsma, "Manoah's wife in 
Judges 13. A model for Israel”, The Bible Today 31 (1993), 209; Reinhartz, a $w, 26$.

14 Exum, $a w, 1980,46$.

15 Verskillende redes vir die vrou se naamloosheid is al aangebied: Exum, $a w$, 1980, 48 aanvaar haar naamloosheid, hoewel met 'n groot vraagteken daaragter; vergelyk ook Schaafsma, $a w, 209$ wat dit toeskryf aan patriargale denke; Reinhartz, $a w, 25-37$ koppel dit aan die vrou se verbintenis en ooreenkomste met die Engel.

16 Vergelyk onder andere $\mathrm{M}$ Bal, Death and dissymmetry. The politics of coherence in the book of Judge, Chicago/London 1988, 74-76; Exum, $a w$, 1980, 48, 58-59; L R Klein, The triumph of irony in the book of Judges, Sheffield 1989, 114; Reinhartz, $a w, 25-37$; Schaafsma, $a w, 209$.

17 Veral Bal, Niditch en onderliggend ook by Klein en Reinhartz.

18 Niditch, $a w, 613$ sê tereg Simson "is a bridge between what humans have transformed, neatened, shaped, institutionalized, and socialized (die Manoagtipe - $J H C$ ), and what is found in nature, wild and nonsocial".

19 Bal, $a w, 74-75$.

20 B G Webb, The book of the Judges. An integrated reading, Sheffield 1987, 173174.

21 Die motief kom voor in $13: 16,21 ; 14: 4,9,16 ; 16: 5,20$.

22 Verskeie geleerdes is van mening dat die ontmoeting tussen die vrou en die Engel 'n seksuele konnotasie het: Bal, $a w$, 74; Klein, $a w, 112-115$; Reinhartz, $a$ w, 33-35; O Margalith, “More Samson legends”, VT 36/4 (1986), 397-405. In die lig van huweliksgebruike en wette en die feit dat Manoag se vrou gretig is om aan haar man oor haar die ontmoetings met die Engel te rapporteer, is dit hoogs onwaarskynlik dat hier van seksuele omgang tussen die Engel en die vrou sprake is.

23 Exum, $a w, 1981,27$, voetnota 13.

24 Niditch, $a w, 614-615$.

$25 \quad$ Klein, $a w, 110$.

26 Exum, $a w, 1980,47$.

27 Reinhartz, $a w, 35-36$. 
$28 \quad$ Klein, $a w, 119$.

29 R de Vaux, Ancient Israel. Its life and institutions, London 21968, 41.

30 De Vaux, $a w, 41$.

31 Bal, $a w, 74-76$ se aanname dat daar seksuele kommunikasie tussen die Engel en die vrou van Manoag was en dat Manoag nie die biologiese vader van Simson was nie, berus op gegewens wat nie bewys kan word nie. So ook is Klein, $a w$, 111-115 se poging om met behulp van die analisering van die taalgebruik in die teks van Rigters 13 en vergelykbare materiaal aan te toon dat konsepsie plaasgevind het tydens die Engel se gesprek met Manoag se vrou, 'n futiele poging om die normale seksuele gemeenskap tussen Manoag en sy vrou weg te redeneer. Die wonderaspek lê daarin dat God dit vir die vrou biologies moontlik maak om op 'n normale wyse ' $n$ kind in die lewe te bring. Hoe dit gebeur, bly 'n geheim en hou verband met die wonderaspek van die naam van die Engel.

$32 \quad$ Klein, $a w, 116$.

33 E J Hamlin, Judges. At risk in the promised land, Grand Rapids 1990, 131.

34 Schaafsma, $a w, 211$ stel dit dat Manoag die mislukte Israel uitbeeld, terwyl sy vrou die rolmodel is vir hoe Israel behoort te wees.

35 Bal, $a w, 201$ wys op die skelm wyse waarop Simson sy eerste misstap teen sy nasireërskap begaan deur van die heuning uit die dooie leeu te eet en vir sy ouers daarvan te gee sonder om hulle te vertel waar dit vandaan kom. Hierdie insident was eintlik 'n opstand teen sy moeder, want sy het die duurte van sy nasireërskap vasgestel (13:7).

36 Vergelyk Rigters 3:6 wat deel vorm van die boek se inleiding.

37 Klein, $a$ w, 138-139; F E Deist \& W S Vorster, Woorde wat ver kom, Kaapstad 1986, 99. 